\title{
Novel Two MRT Cell Lines Established from Multiple Sites of a Synchronous MRT Patient
}

\author{
YASUMICHI KUWAHARA ${ }^{1}$, TOMOKO IEHARA ${ }^{2}$, EISUKE ICHISE ${ }^{2}$, YOSHIKI KATSUMI ${ }^{2}$, KAZUTAKA OUCHI $^{2}$, \\ KUNIHIKO TSUCHIYA ${ }^{2}$, MITSURU MIYACHI ${ }^{2}$, EIICHI KONISHI ${ }^{3}$, HIROYASU SASAJIMA ${ }^{4}$, \\ SATOAKI NAKAMURA ${ }^{5}$, SHIGEHISA FUMINO ${ }^{6}$, TATSURO TAJIRI ${ }^{6}$, PASCAL D. JOHANN ${ }^{7}$, \\ MICHAEL C. FRÜHWALD ${ }^{8}$, TATSUSHI YOSHIDA ${ }^{1}$, TSUKASA OKUDA ${ }^{1}$ and HAJIME HOSOI ${ }^{2}$ \\ ${ }^{1}$ Department of Biochemistry and Molecular Biology, Graduate School of Medical Science, \\ Kyoto Prefectural University of Medicine, Kyoto, Japan; \\ ${ }^{2}$ Department of Pediatrics, Graduate School of Medical Science, \\ Kyoto Prefectural University of Medicine, Kyoto, Japan; \\ ${ }^{3}$ Department of Pathology, Graduate School of Medical Science, \\ Kyoto Prefectural University of Medicine, Kyoto, Japan; \\ ${ }^{4}$ Department of Neurosurgery, Graduate School of Medical Science, \\ Kyoto Prefectural University of Medicine, Kyoto, Japan; \\ ${ }^{5}$ Department of Radiology, Kansai Medical University, Osaka, Japan; \\ ${ }^{6}$ Department of Pediatric Surgery, Graduate School of Medical Science, \\ Kyoto Prefectural University of Medicine, Kyoto, Japan; \\ ${ }^{7}$ Department of Pediatric Oncology, Hematology and Immunology, \\ University Hospital Heidelberg, Heidelberg, Germany; \\ ${ }^{8}$ University Children's Hospital Augsburg, Swabian Children's Cancer Center, Augsburg, Germany
}

\begin{abstract}
Background/Aim: Malignant rhabdoid tumor $(M R T)$ is a rare, aggressive neoplasm found in young children, caused by inactivation of a single gene, SNF5 (INI1, SMARCB1). MRT cases with multifocal tumors at diagnosis are categorized as synchronous MRT, often with a germline mutation of SNF5. The aim of this study was to establish new models useful in clarifying the biological basis of synchronous MRT. Materials and Methods: We established two novel MRT cell lines, designated as KP-MRT-KS and
\end{abstract}

This article is freely accessible online.

Correspondence to: Tsukasa Okuda, Department of Biochemistry and Molecular Biology, Graduate School of Medical Science, Kyoto Prefectural University of Medicine, 465 Kajii-cho, Hirokoji, Kamigyo-ku, Kyoto 602-8566, Japan. Tel: +81 752515316, Fax: +81 752515315, e-mail: okuda@koto.kpu-m.ac.jp and Hajime Hosoi, Department of Pediatrics, Graduate School of Medical Science, Kyoto Prefectural University of Medicine, 465 Kajii-cho, Hirokoji, Kamigyo-ku, Kyoto 602-8566, Japan. Tel: +81 752515571, Fax: +81 752511399, e-mail: hhosoi@koto.kpu-m.ac.jp

Key Words: Synchronous rhabdoid tumor, cell line, germline mutation, DNA methylation analysis.
KP-MRT-KSa, derived from different lesions and at a different time from a synchronous multifocal 7-month-old female MRT patient. Results: Both cells showed typical morphology of MRT, with a compound genomic mutation in exons 2 and 5 of the SNF5 gene. The exon 2 mutation was found in the germline. Conclusion: These cell lines could serve as powerful tools for unveiling the molecular mechanism of refractory synchronous MRT.

Malignant rhabdoid tumor (MRT) is a rare and aggressive neoplasm encountered in neonates and young children. In 1978 , it was initially described as an unfavorable histological type of renal tumor, a variant of Wilms tumor (1), and subsequently these kidney tumors with characteristic cells showing prominent large nuclei and eosinophilic cytoplasmic inclusion bodies, were re-categorized as malignant rhabdoid tumor of the kidney (2). Soon afterwards, MRT was reported to be a tumor that can arise from any anatomical site (3-5) including CNS that was also called as an atypical teratoid rhabdoid tumor (AT/RT) (6). Although gradual improvement of the clinical outcome has been achieved through extensive clinical trials using various combinatorial chemo- and/or radio-therapies (7), the 5-year overall survival (OS) still remains as low as approximately $50 \%(4,5,8,9)$. 
Bi-allelic inactivation of the SNF5 (SMARCB1, BAF47, and $I N I 1$ ) gene, that encodes a component of the SWI/SNF chromatin remodeling complex on chromosome 22q11.2, has reportedly been found $(10,11)$ in nearly $100 \%$ of MRT and AT/RT cases. Importantly, SNF5 abnormality in MRT appears to be the single most important mutation, and approximately $30 \%$ of children diagnosed with MRT and/or AT/RT exhibit heterogeneous germline inactivation of the SNF5 gene (12). Recently, loss-of-function mutations of the BRG-1 (SMARCA4) gene, which encodes another subunit of the SWI/SNF complex, have been reported in $\sim 5 \%$ of AT/RT and MRT cases without SNF5 mutation (13) as well as in familial rhabdoid patients $(14,15)$.

Bonnin et al. have reported the synchronous occurrence of renal and CNS tumors in six MRT cases (16), followed by occasional reports of similar multifocal MRT cases (8, $11,17)$. Those who carry a germline mutation in either SNF5 or BRG-1 tend to be at greater risks of developing single or multifocal rhabdoid tumors. This inherited condition is known as the rhabdoid tumor predisposition syndrome (RTPS) (18-20). However, synchronous or metachronous multifocal cases of rhabdoid tumors are so scarce that details of the underlying mechanisms for the differential tumorigenesis among multiple primary sites remain unclear.

It was recently reported that ATRTs can be subdivided by unsupervised cluster analyses using methylation arrays into three epigenetically distinct subgroups, based on their genome-DNA methylation patterns: i) ATRT- tyrosinase (TYR), ii) -sonic hedgehog (SHH) and iii) Myelocytomatosis (MYC) subgroups (21-23). Pinto et al. have performed DNA-methylation profiling on their metachronous RT cases and reported that the CNS tumor cells often show methylation profiles distinct from those in extra-CNS tumor cells of the same patient (23). Data obtained by means of DNA methylation profiling are expected to further contribute to new valuable insights for a more profound understanding of molecular mechanisms of ATRTs and extra-CNS MRTs (9).

Cell lines established from tumors generally serve as powerful tools for further characterization of the biological properties of a specific tumor type. As for MRT and AT/RT, around 20 lines worldwide have so far been reported (24-28), including the KP-MRT-NS (29), KP-MRT-HS( 30), KPMRT-YM (31), and the KP-MRT-RY (32) cell line established by us. Although these cell lines are being used by many researchers to explore their pathogenesis, no cell lines have been established from multiple sites from one multifocal rhabdoid tumor patient.

Here, we report a case of a 7-month-old female with synchronous malignant rhabdoid tumor. We also describe and characterize two MRT cell lines newly established from two sites of this patient using genetic and epigenetic analyses.

\section{Materials and Methods}

Patient. A 7-month-old female, who had no family history of neoplasms, was referred to our hospital with the complaints of left upper limb paralysis and Horner's syndrome on the left side of her face. Magnetic resonance imaging (MRI) and computed tomography (CT) scanning showed multi-focal tumors: a tumor of the neck that had invaded the spinal canal on C6/7 and C7/Th1 (Figure 1A), a cerebellar vermis tumor without meningeal metastasis (Figure 1B), and at least two tumors in the left apical pulmonary region (Figure 1C). Biopsied specimens of the neck tumor were examined, and histopathologic analysis established that the tumor cells were round with eccentrically placed nuclei with vesicular chromatin staining, prominent nucleoli, and typical eosinophilic intracytoplasmic inclusion bodies (Figure 1D and E). Immunohistochemical examination showed that the cells stained positive for vimentin, epithelial membrane antigen, smooth muscle actin, cytokeratin 8 (Figure 1F), and cytokeratin AE1/AE3, and negatively for desmin, S100, GFAP and SNF5 (Figure 1G). On the basis of these findings, the histological diagnosis of the specimen was malignant rhabdoid tumor (MRT), and the patient was diagnosed as having synchronous malignant rhabdoid tumor with both a CNS lesion (ATRT) and extra-CNS lesions (eMRT).

The initial treatment consisted of three courses of combination chemotherapy with intrathecal methotrexate. The patient also received radiation therapy to the CNS lesion followed by another course of radiation to the neck lesion between the $2^{\text {nd }}$ and $3^{\text {rd }}$ chemotherapy course. These combination therapies had been effective for the neck tumor, CNS lesion and the lung masses, however, the patient developed hydrocephalus without evidence of CNS fluid metastasis. To control the hydrocephalus, she underwent ventriculoperitoneal (VP) shunt surgery, followed by a 4th course of the chemotherapy, after which brain MRI showed new disseminated tumors in and around the cerebellum and midbrain. Although we changed the chemotherapy regimen and continued the chemotherapy and intrathecal treatment, the CNS tumor rapidly regrew. Her tumor then progressed intraperitoneally accompanied by ascites, and the patient died 10 months after diagnosis.

Cell culture and cell lines. A tumor sample for cell culture was obtained from the neck mass at initial biopsy and a sample of ascitic fluid was obtained after death. Two cell lines were successfully established, one from the neck tumor and one from the ascites fluid, and they were named KP-MRT-KS and KP-MRT-KSa, respectively. Cells were cultured in RPMI 1640 (Wako, Osaka, Japan) containing penicillin $(100 \mathrm{U} / \mathrm{ml})$, streptomycin $(100 \mu \mathrm{g} / \mathrm{ml})$ (Gibco, Thermo Fisher Scientific, Waltham, MA, USA), and 10\% FBS (Gibco, Thermo Fisher Scientific), at $37^{\circ} \mathrm{C}$ and $5 \% \mathrm{CO}_{2}$ in a humidified atmosphere. Four MRT cell lines, TTC549, TTC642, A204 and G401 were kindly provided by Dr Bernard E Weissman (33) form the University of North Carolina at Chapel Hil, USAl. The HeLa cell line was obtained from the Riken Cell Bank (Tsukuba, Japan).

Western blot analysis. Cells were scraped into NP40 buffer [50 mmol/1 Tris (pH 8.0) (Sigma Aldrich, St. Louis, MO, USA), 150 mmol/1 NaCl (Wako), 1\% NP40 (Sigma Aldrich), 0.1\% SDS (Sigma Aldrich), $0.5 \%$ sodium deoxycholate (Sigma Aldrich), 2 mmol/L EDTA (pH 8.0) (Sigma Aldrich), 1x protease inhibitor cocktail (25955-11, Nakalai Tesque, Kyoto, Japan), 20 mmol/1 sodium fluoride (Sigma Aldrich), and $0.2 \mathrm{mmol} / 1$ sodium 

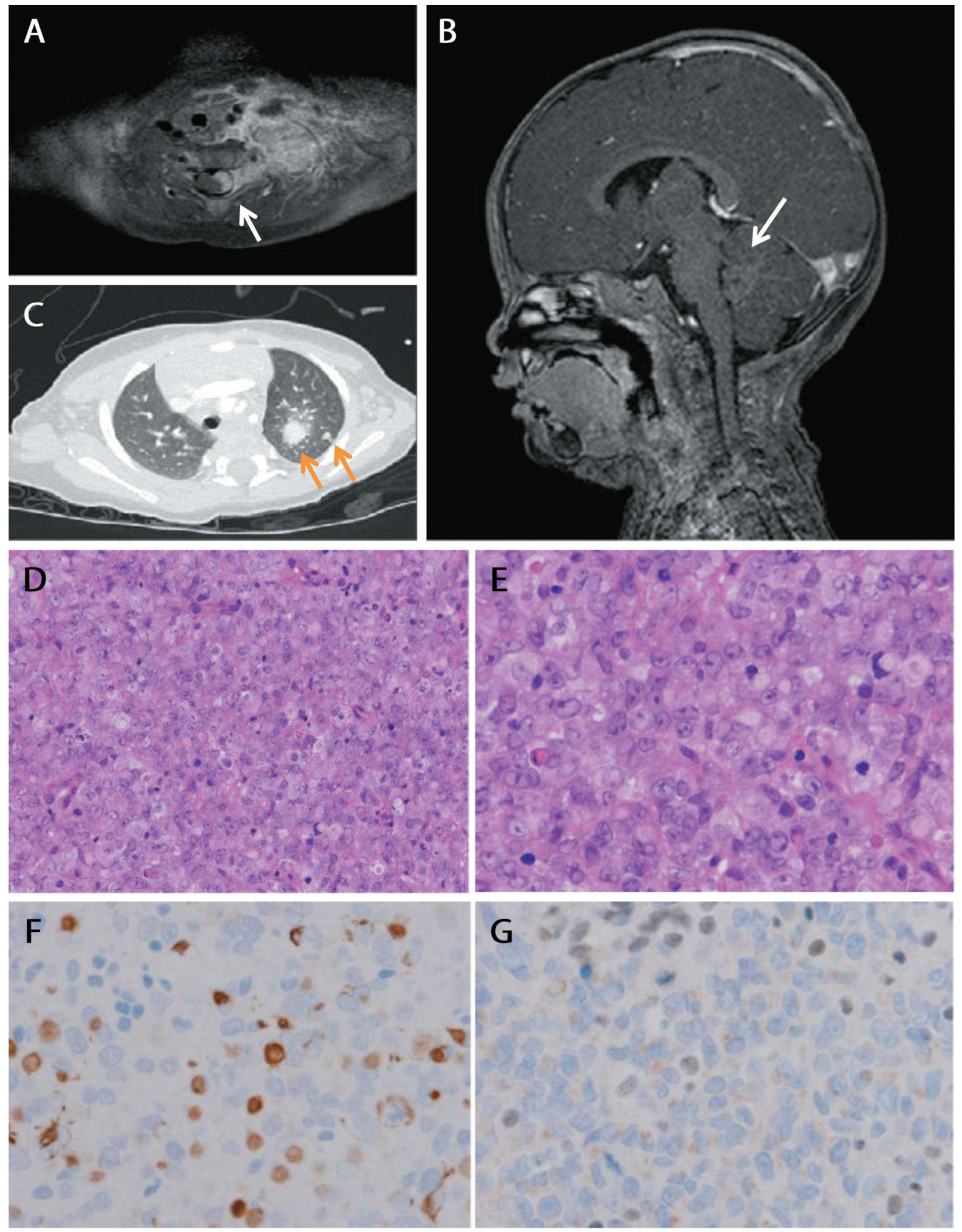

Figure 1. Imaging examination and histopathological findings of the patient prior to treatment. A) Cervical magnetic resonance imaging (MRI) [Gadolinium (Gd) enhanced T1), B) Cranial MRI (Gd enhanced T1), C) Lung computed tomography scan findings. Arrows indicate tumor lesions. D) Hematoxylin and eosin (HE) staining of the biopsied clinical tissues (200x). E) Higher magnifications of the sections in D (400x). F) Immunohistochemical staining of cytokeratin 8 and G) SNF5 (brown color; 200x). 


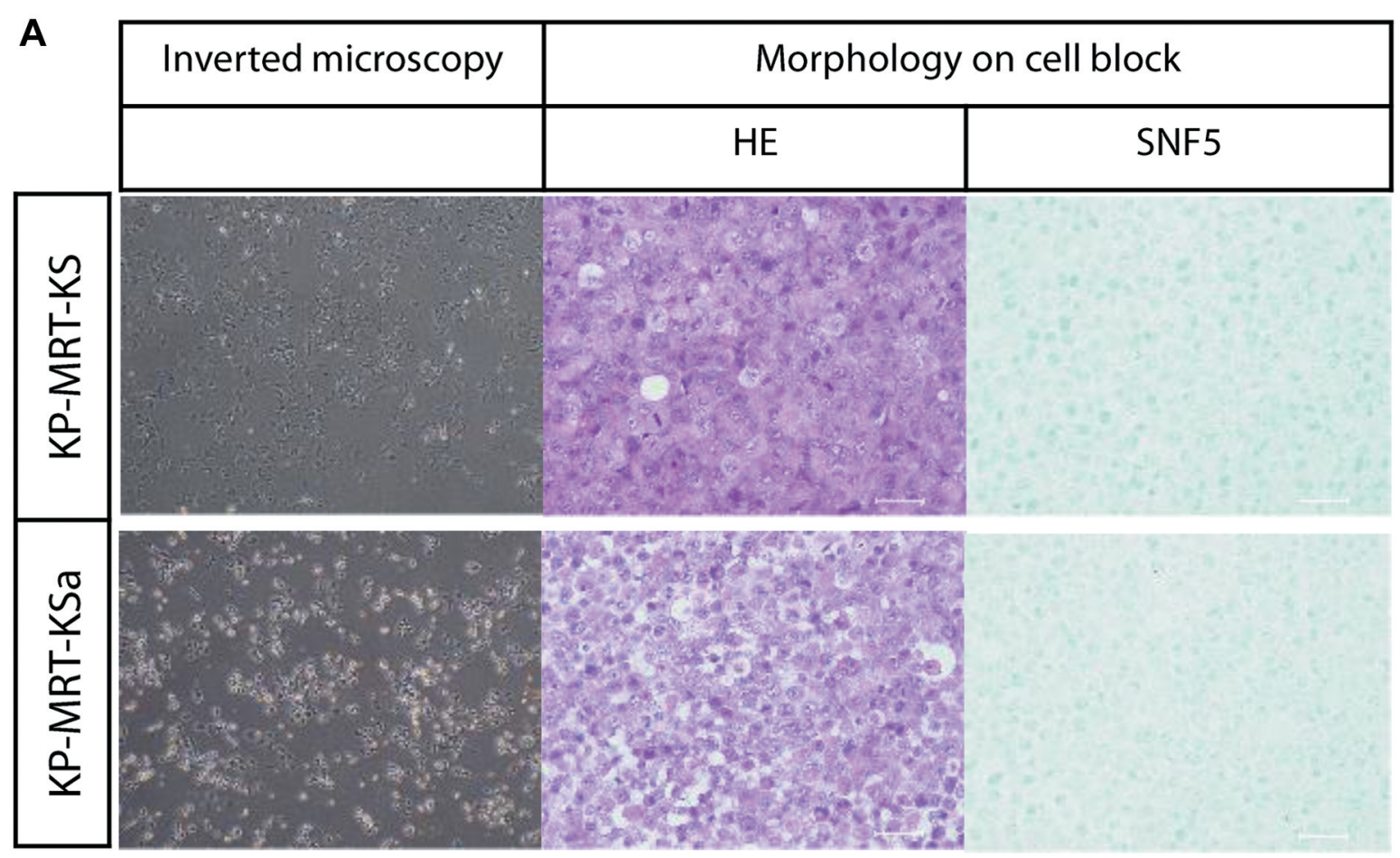

B

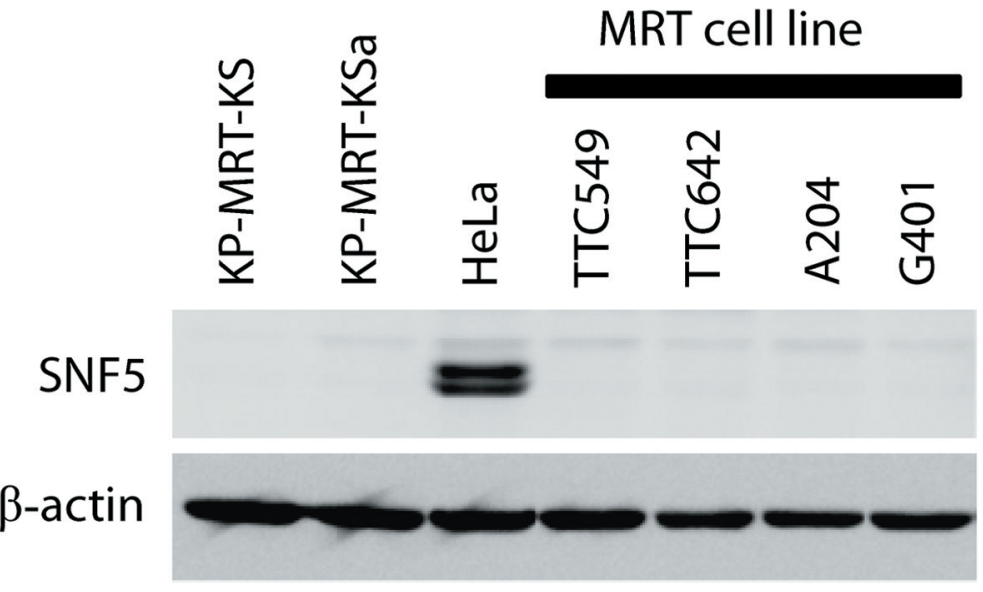

Figure 2. Structure and histopathological findings of KP-MRT-KS and KP-MRT-KSa cell lines. A) Images obtained with inverted microscopy showing spindle-shaped cells with processes and flat cells. HE and immunohistochemical staining for SNF5 on constructed cell blocks. (B) Western blotting analysis of SNF5 and $\beta$-actin expression in indicated cell lines.

orthovanadate (Sigma Aldrich)], and incubated for 30 minutes on ice. Thirty $\mu \mathrm{g}$ of protein was separated by electrophoresis on $10 \%$ SDS-polyacrylamide gels and electro-transferred onto nitrocellulose membranes (GE Healthcare, Chicago, IL, USA). Proteins were analyzed by western blotting using anti SNF5 $(1: 1,000,612110$, BD Biosciences, San Jose, CA, USA), anti- $\beta$ actin (1:2,000, PM053, MBL, Nagoya, Japan), and 1:2,000 horseradish peroxidase-conjugated anti-rabbit or anti-mouse IgG (GE Healthcare). Individual proteins were detected using ECL chemiluminescence reagent (GE Healthcare) and ImageQuant LAS 500 (GE Healthcare).
Cytogenetic analyses. Cytogenetic analyses were performed with a short-term culture method (SRL, Inc., Tokyo, Japan). Briefly, mechanically dispersed cells from the tumor or cell lines were cultured for $16 \mathrm{~h}$ with $0.06 \mu \mathrm{g} / \mathrm{ml}$ Colcemid (WAKO) to arrest cell division at metaphase, followed by hypotonic treatment in $0.075 \mathrm{M}$ $\mathrm{KCl}$ for $25 \mathrm{~min}$. The cells were then fixed with methanol-acetic acid $(3: 1, v / v)$. The karyotype was analyzed by conventional G-banding.

Histological examination of biopsied specimens. Four $\mu \mathrm{m}$ sections made from formalin-fixed, paraffin-embedded tumor samples or cell blocks were stained with hematoxylin and eosin. For 

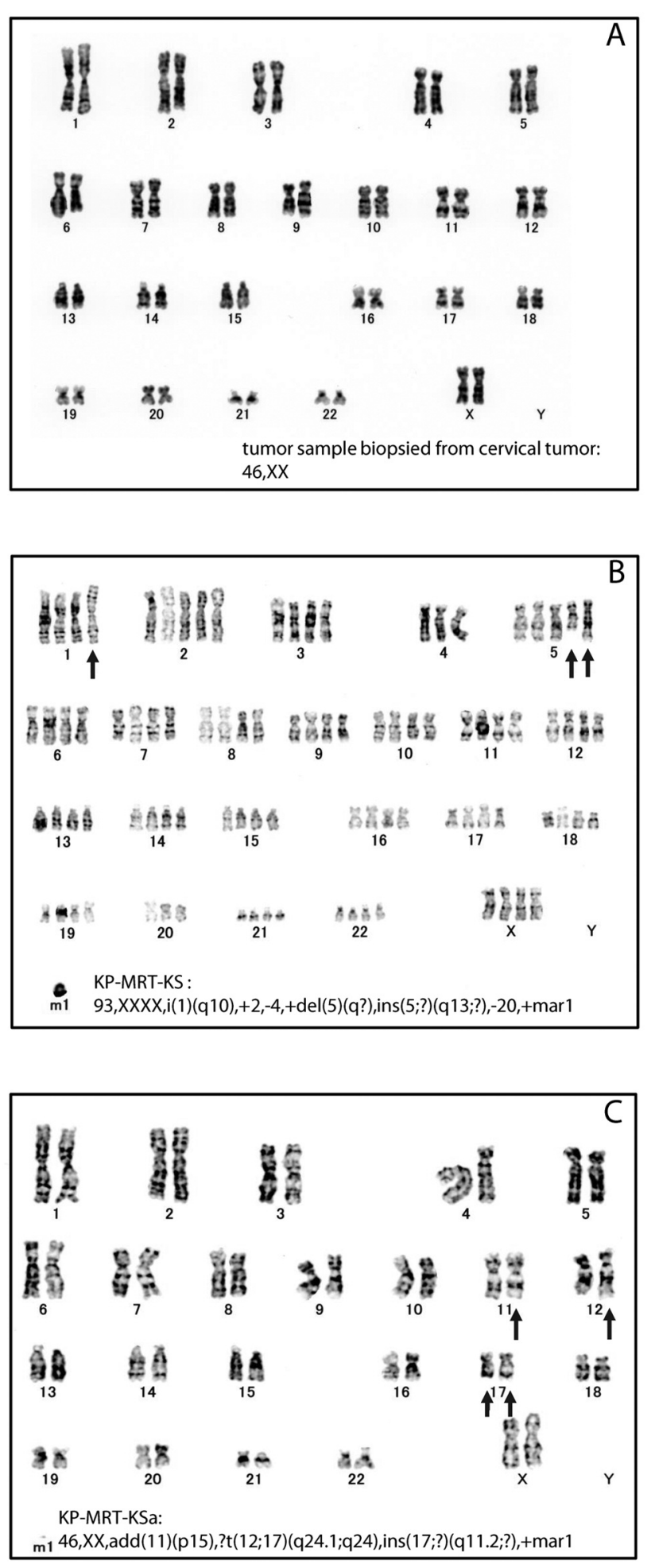

Figure 3. Genetic findings of KP-MRT-KS and KP-MRT-KSa cell lines. Representative karyotype of the two MRT cell lines, using G-banding. A) The karyotype of the tumor sample biopsied from the neck tumor: 46,XX, B) The karyotype of KP-MRT-KS: 93,XXXX,i(1)(q10),+2,$4,+\operatorname{del}(5)(q ?), \operatorname{ins}(5 ; ?)(q 13 ; ?),-20,+$ marl,$C)$ The karyotype of KP-MRTKSa: 46,XX,add(11)(p15),?t(12;17)(q24.1;q24),ins(17;?)(q11.2;?),+mar1. immunohistochemical analysis of clinical samples we used the automated Ventana Benchmark Ultra platform (Roche, Basel, Switzerland) as described previously (34). The sections were immuno-stained with i) vimentin (1:400, M7020, DAKO Denmark A/S, Glostrup, Denmark), ii) epithelial membrane antigen (1:200, M0613, DAKO), iii) smooth muscle actin (1:2,000, A2547, SigmaAldrich, St. Louis, MO, USA), iv) cytokeratin 8 (1:100, NCL-LCK8-TS1, Leica Biosystems Inc., Lincolnshire, IL, USA), v) cytokeratin AE1/AE3 (1:100, NCL-L-AE1/AE3, Leica Biosystems), vi) desmin (1:100, M0760, DAKO), vii) S100 (1:2,000, Z0311, DAKO), viii) GFAP $(1: 2,000, \mathrm{~N} 1506$, DAKO), or ix) SNF5 (1:2,000, ab58209, Abcam, Cambridge, UK). Written informed consent for use of clinical samples for research was obtained from the patient's parents according to the protocol approved by the institutional review board of Kyoto Prefectural University of Medicine in accordance with the Declaration of Helsinki.

DNA extraction and sequencing analysis; DNA methylation profiling by $850 \mathrm{k}$ array. Cells were suspended in an aliquot of Tris/EDTA/NaCl buffer (10 mM Tris pH8.0, 10 mM EDTA pH 8.0 and $100 \mathrm{mM} \mathrm{NaCl}$ ) with $0.5 \%$ SDS (Sigma Aldrich) and proteinase $\mathrm{K}$ (Sigma Aldrich), and incubated at $55^{\circ} \mathrm{C}$ for $3 \mathrm{~h}$, after which the genomic DNA was isolated using a phenol extraction protocol. Briefly, equal volume of Tris-EDTA buffered phenol (WAKO) was added and the mixture was spun down at $14000 \mathrm{rpm}$ for 1 minute. The upper aqueous layer containing DNA was transferred to new tube and mixed with equal volume of chloroform. The mixture was centrifuged at $14000 \mathrm{rpm}$ for 1 minute. Then, DNA contained in the aqueous layer was isolated after ethanol precipitation. Sanger sequencing of the genomic DNA was performed with the aid of the BigDye Terminator v1.1 Cycle Sequencing kit (Applied Biosystems, Foster City, CA, USA) and the ABI PRISM 3500 Sequence Detection System (Applied Biosystems). The primer sequences used for sequencing SNF5 gene exons were kindly provided by Dr Jaclyn A. Biegel (Children's Hospital Los Angeles) (11). DNA methylation patterns of cell lines were assessed using Illumina Human Methylation850 Bead Chip arrays at the Genomics and Proteomics Core Facility of the German Cancer Research Center (DKFZ), according to the manufacturer's instructions. Methylation analysis and unsupervised hierarchical subgrouping was carried out as described previously (21).

Reverse transcription-PCR and single allele analysis. Total RNA was isolated from cultured cells and lymphocytes using the ISOGEN Kit (Nippon Gene, Tokyo, Japan). Single stranded cDNA synthesis from $20 \mu \mathrm{g}$ of template RNA with Oligo-dT (20) was performed using the SuperScript IV First-Strand Synthesis System according to the manufacturer's instructions (18091050, Thermo Fisher Scientific). For RT-PCR amplification of cDNA, which corresponds to $1 \mu \mathrm{g}$ RNA, AmpliTaq Gold 360 polymerase (Thermo Fisher Scientific) was used according to the manufacturer's instructions. A pair of primers to amplify full-length SNF5/INI cDNA were designed according to the procedure described by Biegel et al. (11): INI1CD1 Forward: 5'CTGAGCAAGACCTTCGGGCAG-3'; and INI1CD1 Reverse: 5'GATGGCTGGCACAAACGTCAG-3'. The PCR products obtained with the INI1CD1 primer set were inserted into a T-vector (pRC 2.1 Vector, K2020, Thermo Fisher Scientific) according to the manufacturer's instructions. DH5 $\alpha$ competent $E$. coli cells were subsequently transformed with the ligated vector that contains the 
A

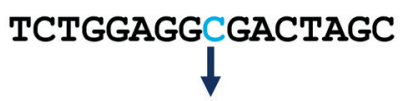

T

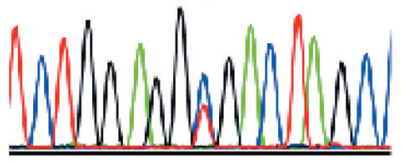

c.157C > T
515253

TCTGGAGGCGACTAGC

W $\quad R \quad R$

515253

TCTGGAGGTGACTAGC

W $\stackrel{\text { R }}{\stackrel{*}{*}}$

B

190

AGGTGCTGGTCCCCATCCGGCTGGACATGGAGATCGATGGGCAGAAGCTGCGAGACGCCTTCACCTGGAACATGAATGAG

$\mathbf{R}$

190

AGGTGCTGGTCCCCATCCGAGGTGCTGGTCCCCATCCGGCTGGACATGGAGATCGATGGGCAGAAGCTGCGAGACGCCTTCACCTGGAACATGAATGAG

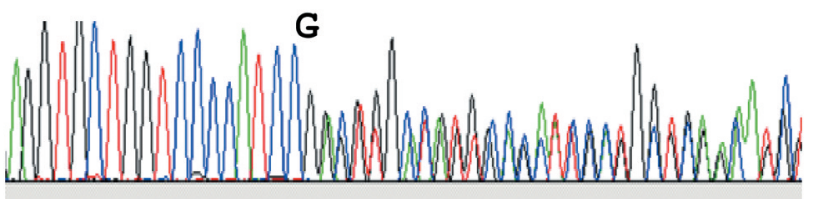

\section{C.551_569dup19}

Figure 4. Chromatograms of DNA sequencing indicating alterations of the SNF5 gene for both KP-MRT-KS and KP-MRT-KSa cell lines. The mutation in exon $2(c .157 C>T)$ and the duplication in exon 5 (c.551_569dup19) were observed in both KP-MRT-KS and KP-MRT-KSa cell lines. A) $C \rightarrow T$ transition resulted in a nonsense mutation at codon 157 (p.Arg53X). B) Duplication of 19 bp resulted in a frameshift mutation (p.Arg190ProfsX27), causing the introduction of a premature stop codon.

PCR products. Plasmid DNAs were then extracted from each single transformed colony and sequenced so that SNF5 coding sequences per single allele could be differentially analyzed.

Growth curves of the cell lines in vitro. The in vitro growth rates of the cell lines were assessed as previously described (35). Briefly, cells $\left(5 \times 10^{4}\right)$ were plated in the RPMI1640 containing $10 \%$ FBS in triplicate and placed into 24 -well cell dishes. Cells were harvested by trypsinization every $24 \mathrm{~h}$ and counted using a hemocytometer. In Brief, cell suspension was placed between the hemocytometer and cover glass, and the cell number was counted by use of an inverted microscope.

In vivo growth assay. Six-week old female athymic mice (BALB/c, $\mathrm{nu} / \mathrm{nu})$ were injected subcutaneously at the dorsal area with aliquots of $200 \mu \mathrm{l}\left(1 \times 10^{6} \mathrm{cells} / \mathrm{site}\right)$ of the cell suspension. The mice were monitored daily for signs of distress and measured for tumor development. Tumor diameters were serially measured with calipers, and tumor volumes were calculated using the formula: $\pi / 6 \times$ (larger

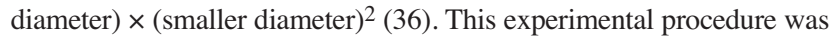
approved by the Committee for Animal Research, Kyoto Prefectural University of Medicine. After the tumors grew sufficiently, the mice were euthanized and their xenografts were histologically examined.

\section{Results}

Establishment of the KP-MRT-KS and KP-MRT-KSa cell lines. KP-MRT-KS and KP-MRT-KSa cells had a round or spindle-shaped appearance and grew in an adherent monolayer, as previously described for several human MRT cell lines (Figure 2A) $(27,29,33)$. The cell cultures were maintained for more than 50 passages over a 3-year period, suggesting that they have attained immortality as cell lines. We performed histological examinations using cell blocks constructed from these two cell lines. The cells were small and round with vesicular nuclei, prominent nucleoli, and a typical eosinophilic cytoplasmic inclusion body observed in both cell lines (Figure 2A). Furthermore, both cell lines were immunohistochemically positive for vimentin and cytokeratin AE1/AE3 and negative for S100 or GFAP. These findings show that the characteristics of both cell lines are consistent with those of tumor cells from the primary cervical MRT tumor specimens (Figure 1E). We also found that SNF5 was not expressed in cell block specimens from KP-MRT-KS and 
KP-MRT-KSa cell lines (Figure 2A). As expected, Western blot analysis showed the SNF5 protein was absent from these two cell lines as well as from the four comparative MRT cell lines, in comparison with the SNF5-positive HeLa cell line (Figure 2B). These results indicate that the KP-MRT-KS and KP-MRT-KSa cell lines retained their characteristics as MRT cells manifested in the original tumor.

Loss of SNF5 expression and its gene alternations in cell lines. Next, we analyzed the mechanism of the loss of SNF5 expression. We first used cytogenetic G-banding analysis to analyze the karyotypes of the KP-MRT-KS and KP-MRT-KSa cell lines as well as of the original tumor sample biopsied from the neck tumor. The original tumor cells from the neck lesion showed a normal female karyotype, 46, XX (Figure 3A). In contrast, as shown in Figure 3B, KP-MRT-KS cell line showed 93, XXXX, i(1)(q10), +2, -4, +del(5)(q?), ins(5;?)(q13;?), -20, + mar1, indicating it was a hypo-tetraploid karyotype. Also, the KP-MRT-KSa cell line showed 46, XX, add(11)(p15), $\mathrm{t}(12 ; 17)(\mathrm{q} 24 ; 1 ; \mathrm{q} 24)$, ins(17;?)(q11.2;?), indicating it was a diploid karyotype with a few chromosomal abnormalities (Figure 3C). Both cell lines as well as the primary tumor cells showed, as determined by microscopic examination, that there were no alterations of chromosome 22 where the SNF5 gene localizes.

We then evaluated the SNF5 gene status by direct sequencing of the genomic DNA of each of the corresponding exons of SNF5. A mutation in exon 2 (c.157 $\mathrm{C}>\mathrm{T}$ ) and a duplication in exon 5 (c.551_569dup19) were observed in both the KP-MRT-KS and KP-MRT-KSa cell lines. The $\mathrm{C} \rightarrow \mathrm{T}$ transition had resulted in a nonsense mutation at codon 157 (p.Arg53X) (Figure 4A). The duplication of $19 \mathrm{bp}$ had caused a frameshift mutation (p.Arg190ProfsX27), resulting in a premature stop codon (Figure 4B).

Importantly, these mutations in SNF5 exons existed on different alleles. PCR products, amplified from cDNA reverse-transcribed from mRNA of either of the two cell lines and with a primer set encompassing from exon 1 to exon 6 (INI1CD1), had either the mutation in exon 2 or the duplication in exon 5 in a mutually exclusive fashion.

We confirmed that the primary neck tumor cells carried the same compound mutation in exons 2 and 5 for both SNF5 alleles in their genomic DNA, while only the exon 2 mutation was present, and not the exon 5 duplication, in the genomic DNA samples extracted from the patient's white blood cells. Additional examination of family members was not possible because their consent could not be obtained. Considering the fact that no other family members had developed MRT or other pediatric tumors, we postulate that the patient had been suffering from synchronous tumors in multiple sites, as a case of RTPS with a de novo germline mutation in exon 2 .
DNA methylation profiling of cell lines. To determine the molecular subgroups of these cell lines, we used the Illumina Infinium Human $850 \mathrm{~K}$ bead array for an unsupervised hierarchical clustering analysis of genome-wide DNA methylation. The resulting findings demonstrated that these cell lines could be classified as an MYC subgroup (Figure $5 \mathrm{~A}$ ). This result was further substantiated by a t-distributed stochastic neighbor embedding (tSNE)based analysis, (Figure 5B), suggesting that these cell lines had originated from the same cell population.

In vitro and in vivo characterization of cell lines using a xenograft model. We further examined whether these cell lines show different growth properties in culture. Figure 6A shows similar growth rates for their proliferation in culture with doubling time of approximately $48 \mathrm{~h}$ for both cell lines.

We next assessed the ability of each cell line to form tumors in immunocompromised mice after subcutaneous inoculation. As shown in the right panel of Figure $6 \mathrm{~B}$, on day 7 after injection two of the four mice that had $1 \times 10^{6} \mathrm{KP}$ MRT-KSa cells injected showed a single subcutaneous mass. Four weeks after injection, these two xenograft masses had grown exponentially, and 98 days after injection, the xenografted mice were sacrificed, followed by resection of the tumors (Figure 6C). On the other hand, none of the four mice that had $1 \times 10^{6}$ KP-MRT-KS cells injected had developed tumors even by day 28 after injection (Figure $6 \mathrm{~B}$, left panel). We therefore injected an additional $4 \times 10^{6} \mathrm{KP}$ MRT-KS cells on the site opposite to the previous injection site. Although two of these four mice developed small palpable masses, these were transient and eventually disappeared. Since no tumors developed in any of the four mice injected with KP-MRT-KS cells, these cells showed a difference with KP-MRT-KSa cells (Figure 6B, left panel).

Histological examination revealed that the tumors derived from the KP-MRT-KSa cell line contained small round cells with a typical eosinophilic intracytoplasmic inclusion body with negative SNF5 stain, a finding which resembled that for the original tumor (Figure 6C).

\section{Discussion}

As a result of the study presented here, we could establish a pair of MRT cell lines, KP-MRT-KS and KP-MRT-KSa, that were derived from two different sites of a synchronous MRT patient suffering from RTPS, displaying similar histological and genetic findings to the characteristic features of the tumor cells from which the cell lines were derived.

The definition of RTPS specifies the presence of multiple Rhabdoid tumors and molecular identification of a germline heterozygous pathogenic variant allele, either SNF5 or SMARCA4 (Brg-1) (13). Thus, it has been indicated that significant genes for tumor development exist not only in 


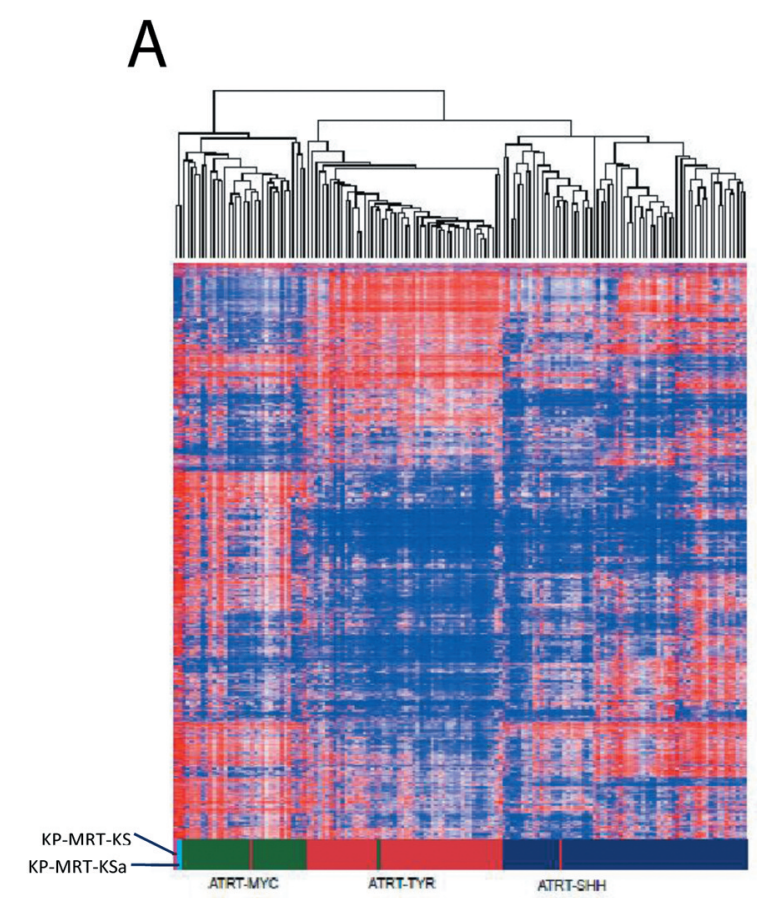

B

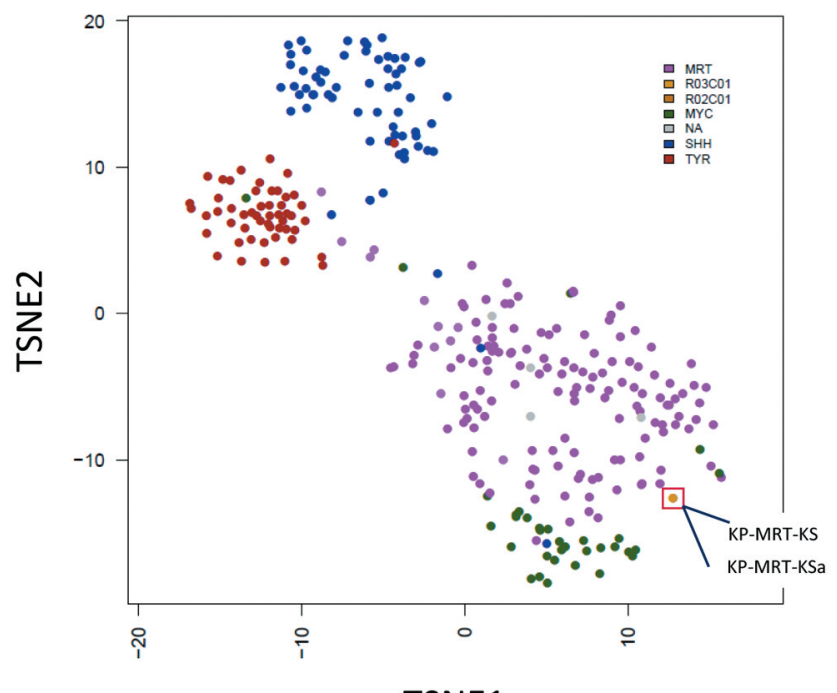

Figure 5. Identification by means of unsupervised cluster analyses of three distinct molecular subgroups of atypical teratoid rhabdoid tumor (ATRT). A) Unsupervised hierarchical clustering of ATRT methylation profiles. Both cell lines could be classified as an ATRT-MYC subgroup. B) A tdistributed stochastic neighbor embedding (tSNE)based analysis revealed that both cell lines were displayed at almost the same position.

somatic mutatiosn but also in germline mutations (37). In our patient, a point-mutation in exon 2 of the SNF5 gene (c.157 $\mathrm{C}>\mathrm{T}$ ) was identified as a germline mutation. On the other hand, a duplication in exon 5 of the SNF5 gene (c.551_569dup19) had arisen in tumor cell as an additional somatic mutation during the first step in tumor initiation. Taken together, our case is compatible with RTPS with synchronous tumors having a de novo germline mutation in exon 2 in multiple sites.

The presence of the non-sense nucleotide substitution c.157 C $>\mathrm{T}$ in exon 2 has been previously reported in two cases of RTPS $(19,32)$ in another tumor cell line, KP-MRT$\mathrm{RY}$, derived from the patient. Eaton et al. have also reported genomic duplication, c.548_566dup19 and c.553_565dup13 (19), which generate a premature stop codon that is similar to the c.551_569dup19 of the present case. Although it is possible that there are hot spots for mutations in the SNF5 gene, which may feature a geographical distribution, the exact frequencies and variations of SNF5 gene alterations have not yet reported in any Japanese studies. Further examinations are, thus, needed to clarify those points with regard to Japanese patients.

As for the question where the relapsed disseminating CNS lesions occurred in our patient, DNA methylation profiling analysis and precise genotyping provided the answer. Pinto et al. have demonstrated that the DNA methylation signature of the genomic DNA differs between CNS and extra-CNS lesions in most cases of synchronous or metachronous multifocal MRT tumors, even if these carry the same SNF5 alteration (23). In our case, the KPMRT-KSa cells from ascites, containing relapsed CNS tumor cells and KP-MRT-KS cells from the neck tumor, showed similar DNA methylation and gene expression patterns. From this point of view, the relapsed CNS lesions may have originated as a result of metastasis from the MRT neck tumor after treatment, although the possibility remains that the former lesion was derived from the initial cerebellum lesion. Nevertheless, the important point is that these two cell lines also had the same compound gene alteration, thus, providing further evidence that these two cell populations originated from a single cell. These findings show that DNA methylation profiling analysis should serve as a useful tool not only for detecting MRT subgroups but also for investigating the pathogenesis of synchronous MRT patients. Elucidation of the mechanisms through which epigenetic aberrations develop due to SNF5 loss could lead us to a more profound understanding of MRT tumorigenesis.

Although KP-MRT-KS and KP-MRT-KSa cells have a similar epigenetic background, as evidenced by the DNA methylation results, and share the same compound genetic alteration at the SNF5 loci, their tumorigenic capability in 


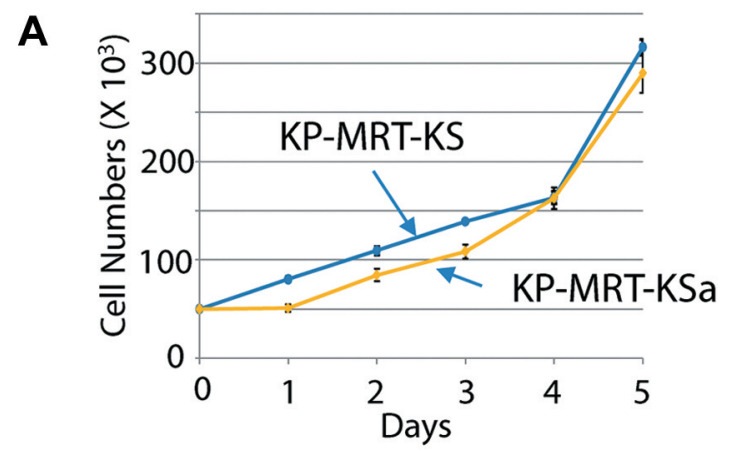

B
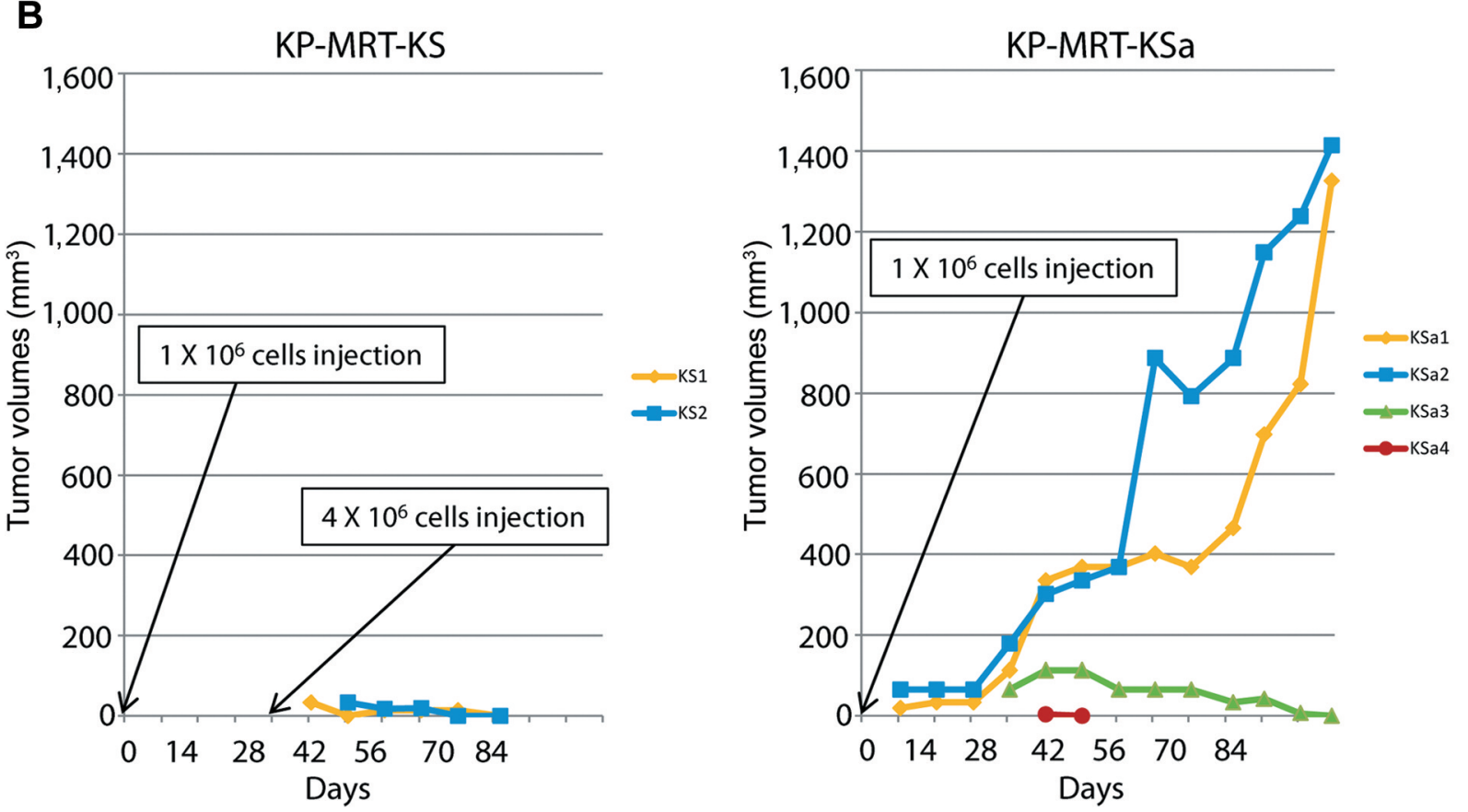

C

$\mathrm{KSa} 2 \mathrm{KSa} 1$

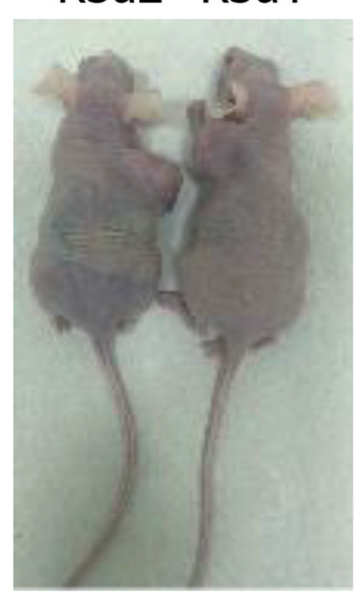

D
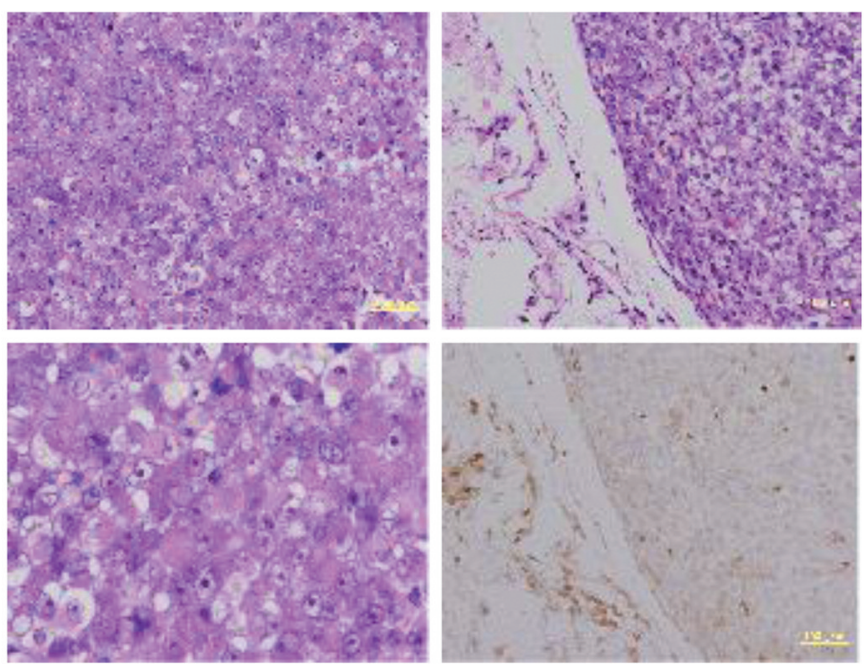

Figure 6. Cell growth characteristics and tumorigenicity of KP-MRT-KS and KP-MRT-KSa cell lines in vitro and in vivo. (A) Cell growth in vitro. Both cell lines showed similar growth rates (proliferation) in culture. B) Xenograft model. Tumors developed in two of the four mice injected with KP-MRT-KSa cells, but no tumor developed in any of the mice with KP-MRT-KS cells. (C) Two representative athymic mice with subcutaneous tumor inoculated with KP-MRT-KSa cells. D) Histopatological findings of the KSal tumor. Left column shows H\&E staining (top row: 200x, bottom row: 400x) and right column shows images of the KSal tumor with SNF5 immunostaining (top row: H\&E, bottom row: SNF5; brown colour). 
vivo showed sharp differences. It is possible that KP-MRT$\mathrm{KSa}$ cells, which were obtained at the end of the clinical course, may have undergone additional mutations that may have contributed to their survival and/or growth potential to resist anti-tumoral agents or irradiation. Further examination of the genomic differences between KP-MRT-KS and KPMRT-KSa cells can thus be expected to lead to a more detailed understanding of the mechanisms of resistance to chemotherapy and radiation therapy.

In conclusion, this is the first report describing the establishment of a pair of cell lines from a synchronous MRT patient with RTPS. Now that MRT cell lines with their distinct epigenetic signature are becoming available, including the two cell lines described in this report, these will surely contribute to further elucidation of the tumorigenesis mechanism in relation to the epigenetic control of this aggressive and dismal pediatric tumor.

\section{Conflicts of Interest}

The Authors declare no potential conflicts of interest.

\section{Authors' Contributions}

YKu, YKa, KO, EK, TY, and JDP carried out the experiments, analyzed the data and prepared the manuscript. YKu, EI, MM, TI, HS, SN, SF, and TT were in charge of the treatment of the patient. $\mathrm{MCF}, \mathrm{HH}$ and $\mathrm{TO}$ edited and approved the manuscript.

\section{Acknowledgements}

The Authors would like to thank Drs. Martin Hasselblatt, Kenta Yamasaki, Kenjiro Tadagaki, and Noriko Kondo for their useful comments regarding the experiments.

\section{Grant Support}

This study was supported in part by grants from the JSPS Kakenhi Grants-in-Aid program (numbers JP15K09487, JP16K10038, JP19K08257, and JP19K08846), and financial support for research projects related to childhood cancer by the Children's Cancer Association of Japan.

\section{References}

1 Beckwith JB and Palmer NF: Histopathology and prognosis of wilms tumors: Results from the first national wilms' tumor study. Cancer 41(5): 1937-1948, 1978. PMID: 206343. DOI: 10.1002/ 1097-0142(197805)41:5<1937::aid-cncr2820410538>3.0.co;2-u

2 Haas JE, Palmer NF, Weinberg AG and Beckwith JB: Ultrastructure of malignant rhabdoid tumor of the kidney. A distinctive renal tumor of children. Hum Pathol 12(7): 646-657, 1981. PMID: 7275104. DOI: 10.1016/s0046-8177(81)80050-0

3 D'Angio GJ, Breslow N, Beckwith JB, Evans A, Baum H, deLorimier A, Fernbach D, Hrabovsky E, Jones B, Kelalis P, Othersen HB, Teft M and Thomas PRM: Treatment of Wilms' tumor. Results of the third National Wilms' Tumor Study. Cancer 64(2): 349-360, 1989. PMID: 2544249. DOI: 10.1002/10970142(19890715)64:2<349::aid-cncr2820640202>3.0.co;2-q

4 Reinhard H, Reinert J, Beier R, Furtwangler R, Alkasser M, Rutkowski S, Fruhwald M, Koscielniak E, Leuschner I, Kaatsch $\mathrm{P}$ and Graf N: Rhabdoid tumors in children: Prognostic factors in 70 patients diagnosed in germany. Oncol Rep 19(3): 819-823, 2008. PMID: 18288421. DOI: 10.3892/or.19.3.819

5 Sultan I, Qaddoumi I, Rodriguez-Galindo C, Nassan AA, Ghandour K and Al-Hussaini M: Age, stage, and radiotherapy, but not primary tumor site, affects the outcome of patients with malignant rhabdoid tumors. Pediatr Blood Cancer 54(1): 35-40, 2010. PMID: 19798737. DOI: 10.1002/pbc.22285

6 Rorke LB, Packer R and Biegel J: Central nervous system atypical teratoid/rhabdoid tumors of infancy and childhood. $\mathrm{J}$ Neurooncol 24(1): 21-28, 1995. PMID: 8523069. DOI: 10.1007/BF01052653

7 Bartelheim K, Nemes K, Seeringer A, Kerl K, Buechner J, Boos J, Graf N, Durken M, Gerss J, Hasselblatt M, Kortmann RD, Teichert von Luettichau I, Nagel I, Nygaard R, Oyen F, Quiroga E, Schlegel PG, Schmid I, Schneppenheim R, Siebert R, SolanoPaez P, Timmermann B, Warmuth-Metz M and Fruhwald MC: Improved 6-year overall survival in AT/RT - results of the registry study rhabdoid 2007. Cancer Med 5(8): 1765-1775, 2016. PMID: 27228363. DOI: $10.1002 / \mathrm{cam} 4.741$

8 Tomlinson GE, Breslow NE, Dome J, Guthrie KA, Norkool P, Li S, Thomas PR, Perlman E, Beckwith JB, D'Angio GJ and Green DM: Rhabdoid tumor of the kidney in the National Wilms' Tumor Study: Age at diagnosis as a prognostic factor. J Clin Oncol 23(30): 7641-7645, 2005. PMID: 16234525. DOI: $10.1200 /$ jco.2004.00.8110

9 Fruhwald MC, Hasselblatt M, Nemes K, Bens S, Steinbugl M, Johann PD, Kerl K, Hauser P, Quiroga E, Solano-Paez P, Biassoni V, Gil-da-Costa MJ, Perek-Polnik M, van de Wetering M, Sumerauer D, Pears J, Stabell N, Holm S, Hengartner H, Gerber NU, Grotzer M, Boos J, Ebinger M, Tippelt S, Paulus W, Furtwangler R, Hernaiz-Driever P, Reinhard H, Rutkowski S, Schlegel PG, Schmid I, Kortmann RD, Timmermann B, Warmuth-Metz M, Kordes U, Gerss J, Nysom K, Schneppenheim R, Siebert R, Kool M and Graf N: Age and DNA-methylation subgroup as potential independent risk factors for treatment stratification in children with atypical teratoid/rhabdoid tumors. Neuro Oncol, 2019. PMID: 31883020. DOI: 10.1093/neuonc/noz244

10 Versteege I, Sevenet N, Lange J, Rousseau-Merck MF, Ambros P, Handgretinger R, Aurias A and Delattre O: Truncating mutations of hsnf5/ini1 in aggressive paediatric cancer. Nature 394(6689): 203-206, 1998. PMID: 9671307. DOI: 10.1038/28212

11 Biegel JA, Zhou JY, Rorke LB, Stenstrom C, Wainwright LM and Fogelgren B: Germ-line and acquired mutations of INI1 in atypical teratoid and rhabdoid tumors. Cancer Res 59(1): 74-79, 1999. PMID: 9892189.

12 Bourdeaut F, Lequin D, Brugieres L, Reynaud S, Dufour C, Doz F, Andre N, Stephan JL, Perel Y, Oberlin O, Orbach D, Bergeron C, Rialland X, Freneaux P, Ranchere D, Figarella-Branger D, Audry G, Puget S, Evans DG, Pinas JC, Capra V, Mosseri V, Coupier I, Gauthier-Villars M, Pierron G and Delattre O: Frequent hSNF5/INI1 germline mutations in patients with rhabdoid tumor. Clin Cancer Res 17(1): 31-38, 2011. PMID: 21208904. DOI: 10.1158/1078-0432.ccr-10-1795 
13 Nemes K, Bens S, Bourdeaut F, Hasselblatt M, Kool M, Johann P, Kordes U, Schneppenheim R, Siebert R and Fruhwald MC: Rhabdoid tumor predisposition syndrome. In: Genereviews ${ }^{\circledR}$. Adam MP, Ardinger HH, Pagon RA, Wallace SE, Bean LJH, Stephens K and Amemiya A (eds.). University of Washington, Seattle, pp. 1993-2020. PMID: 29215836.

14 Hasselblatt M, Gesk S, Oyen F, Rossi S, Viscardi E, Giangaspero F, Giannini C, Judkins AR, Fruhwald MC, Obser $\mathrm{T}$, Schneppenheim R, Siebert $\mathrm{R}$ and Paulus W: Nonsense mutation and inactivation of smarca4 (BRG1) in an atypical teratoid/rhabdoid tumor showing retained SMARCB1 (INI1) expression. Am J Surg Pathol 35(6): 933-935, 2011. PMID: 21566516. DOI: 10.1097/PAS.0b013e3182196a39

15 Schneppenheim R, Fruhwald MC, Gesk S, Hasselblatt M, Jeibmann A, Kordes U, Kreuz M, Leuschner I, Martin Subero JI, Obser T, Oyen F, Vater I and Siebert R: Germline nonsense mutation and somatic inactivation of SMARCA4/BRG1 in a family with rhabdoid tumor predisposition syndrome. Am J Hum Genet 86(2): 279-284, 2010. PMID: 2820190. DOI: 10.1016/j.ajhg.2010.01.013

16 Bonnin JM, Rubinstein LJ, Palmer NF and Beckwith JB: The association of embryonal tumors originating in the kidney and in the brain. A report of seven cases. Cancer 54(10): 2137-2146, 1984. PMID: 6091860. DOI: 10.1002/1097-0142(19841115) 54:10<2137::aid-cncr2820541014>3.0.co;2-d

17 Biegel JA, Tan L, Zhang F, Wainwright L, Russo P and Rorke LB: Alterations of the hSNF5/INI1 gene in central nervous system atypical teratoid/rhabdoid tumors and renal and extrarenal rhabdoid tumors. Clin Cancer Res 8(11): 3461-3467, 2002. PMID: 12429635.

18 Sredni ST and Tomita T: Rhabdoid tumor predisposition syndrome. Pediatr Dev Pathol 18(1): 49-58, 2015. PMID: 25494491. DOI: 10.2350/14-07-1531-misc.1

19 Eaton KW, Tooke LS, Wainwright LM, Judkins AR and Biegel JA: Spectrum of SMARCB1/INI1 mutations in familial and sporadic rhabdoid tumors. Pediatr Blood Cancer 56(1): 7-15, 2011. PMID: 3086793. DOI: 10.1002/pbc.22831

20 Abu Arja MH, Patel P, Shah SH, Auletta JJ, Meyer EK, Conley SE, Aldrink JH, Pindrik JA and AbdelBaki MS: Synchronous central nervous system atypical teratoid/ rhabdoid tumor and malignant rhabdoid tumor of the kidney: Case report of a longterm survivor and review of the literature. World Neurosurg, 2017. PMID: 29223518. DOI: 10.1016/j.wneu.2017.11.158

21 Johann PD, Erkek S, Zapatka M, Kerl K, Buchhalter I, Hovestadt V, Jones DT, Sturm D, Hermann C, Segura Wang M, Korshunov A, Rhyzova M, Grobner S, Brabetz S, Chavez L, Bens S, Groschel S, Kratochwil F, Wittmann A, Sieber L, Georg C, Wolf S, Beck K, Oyen F, Capper D, van Sluis P, Volckmann R, Koster J, Versteeg $\mathrm{R}$, von Deimling A, Milde T, Witt O, Kulozik AE, Ebinger M, Shalaby T, Grotzer M, Sumerauer D, Zamecnik J, Mora J, Jabado N, Taylor MD, Huang A, Aronica E, Bertoni A, Radlwimmer B, Pietsch T, Schuller U, Schneppenheim R, Northcott PA, Korbel JO, Siebert R, Fruhwald MC, Lichter P, Eils R, Gajjar A, Hasselblatt M, Pfister SM and Kool M: Atypical teratoid/rhabdoid tumors are comprised of three epigenetic subgroups with distinct enhancer landscapes. Cancer Cell 29(3): 379-393, 2016. PMID: 26923874. DOI: $10.1016 /$ j.ccell.2016.02.001

22 Torchia J, Golbourn B, Feng S, Ho KC, Sin-Chan P, Vasiljevic A, Norman JD, Guilhamon P, Garzia L, Agamez NR, Lu M, Chan TS, Picard D, de Antonellis P, Khuong-Quang DA, Planello AC,
Zeller C, Barsyte-Lovejoy D, Lafay-Cousin L, Letourneau L, Bourgey M, Yu M, Gendoo DM, Dzamba M, Barszczyk M, Medina T, Riemenschneider AN, Morrissy AS, Ra YS, Ramaswamy V, Remke M, Dunham CP, Yip S, Ng HK, Lu JQ, Mehta V, Albrecht S, Pimentel J, Chan JA, Somers GR, Faria CC, Roque L, Fouladi M, Hoffman LM, Moore AS, Wang Y, Choi SA, Hansford JR, Catchpoole D, Birks DK, Foreman NK, Strother D, Klekner A, Bognar L, Garami M, Hauser P, Hortobagyi T, Wilson B, Hukin J, Carret AS, Van Meter TE, Hwang EI, Gajjar A, Chiou SH, Nakamura H, Toledano H, Fried I, Fults D, Wataya T, Fryer C, Eisenstat DD, Scheinemann K, Fleming AJ, Johnston DL, Michaud J, Zelcer S, Hammond R, Afzal S, Ramsay DA, Sirachainan N, Hongeng S, Larbcharoensub N, Grundy RG, Lulla RR, Fangusaro JR, Druker H, Bartels U, Grant R, Malkin D, McGlade CJ, Nicolaides T, Tihan T, Phillips J, Majewski J, Montpetit A, Bourque G, Bader GD, Reddy AT, Gillespie GY, Warmuth-Metz M, Rutkowski S, Tabori U, Lupien M, Brudno M, Schuller U, Pietsch T, Judkins AR, Hawkins CE, Bouffet E, Kim SK, Dirks PB, Taylor MD, Erdreich-Epstein A, Arrowsmith CH, De Carvalho DD, Rutka JT, Jabado N and Huang A: Integrated (epi)-genomic analyses identify subgroup-specific therapeutic targets in cns rhabdoid tumors. Cancer Cell 30(6): 891-908, 2016. PMID: 27960086. DOI: 10.1016/j.ccell.2016.11.003

23 Pinto EM, Hamideh D, Bahrami A, Orr BA, Lin T, Pounds S, Zambetti GP, Pappo AS, Gajjar A, Agnihotri S and Broniscer A: Malignant rhabdoid tumors originating within and outside the central nervous system are clinically and molecularly heterogeneous. Acta Neuropathol 136(2): 315-326, 2018. PMID: 6063764. DOI: $10.1007 / \mathrm{s} 00401-018-1814-2$

24 Kuwahara Y, Hosoi H, Osone S, Kita M, Iehara T, Kuroda H and Sugimoto T: Antitumor activity of gefitinib in malignant rhabdoid tumor cells in vitro and in vivo. Clin Cancer Res 10(17): 5940-5948, 2004. PMID: 15355927. DOI: 10.1158/ 1078-0432.ccr-04-0192

25 Kuwahara Y, Charboneau A, Knudsen ES and Weissman BE: Reexpression of hSNF5 in malignant rhabdoid tumor cell lines causes cell cycle arrest through a p21 cip1/waf1-dependent mechanism. Cancer Res 70(5): 1854-1865, 2010. PMID: 20179200. DOI: 10.1158/0008-5472.CAN-09-1922

26 Suzuki A, Ohta S and Shimada M: Gene expression of malignant rhabdoid tumor cell lines by reverse transcriptase-polymerase chain reaction. Diagn Mol Pathol 6(6): 326-332, 1997. PMID: 9559292. DOI: 10.1097/00019606-199712000-00004

27 Kuroda H, Moritake H, Sawada K, Kuwahara Y, Imoto I, Inazawa $\mathrm{J}$ and Sugimoto $\mathrm{T}$ : Establishment of a cell line from a malignant rhabdoid tumor of the liver lacking the function of two tumor suppressor genes, hSNF5/INI1 and p16. Cancer Genet Cytogenet 158(2): 172-179, 2005. PMID: 15796965. DOI: $10.1016 /$ j.cancergencyto.2004.08.032

28 Kato H, Ohta S, Koshida S, Narita T, Taga T, Takeuchi Y and Sugita K: Expression of pericyte, mesangium and muscle markers in malignant rhabdoid tumor cell lines: Differentiation-induction using 5-azacytidine. Cancer Sci 94(12): 1059-1065, 2003. PMID: 14662021. DOI: 10.1111/j.1349-7006.2003.tb01401.x

29 Sugimoto T, Hosoi H, Horii Y, Ishida H, Mine H, Takahashi K, Abe T, Ohta S and Sawada T: Malignant rhabdoid-tumor cell line showing neural and smooth-muscle-cell phenotypes. Int J Cancer 82(5): 678-686, 1999. PMID: 10417765. DOI: 10.1002/(sici)1097-0215(19990827)82:5<678::aidijc10>3.0.co; $2-\mathrm{k}$ 
30 Mori T, Fukuda Y, Kuroda H, Matsumura T, Ota S, Sugimoto T, Nakamura $\mathrm{Y}$ and Inazawa $\mathrm{J}$ : Cloning and characterization of a novel Rab-family gene, Rab36, within the region at 22q11.2 that is homozygously deleted in malignant rhabdoid tumors. Biochem Biophys Res Commun 254(3): 594-600, 1999. PMID: 9920784. DOI: $10.1006 /$ bbrc. 1998.9968

31 Misawa A, Hosoi H, Imoto I, Iehara T, Sugimoto T and Inazawa J: Translocation $(1 ; 22)(\mathrm{p} 36 ; \mathrm{q} 11.2)$ with concurrent del(22) (q11.2) resulted in homozygous deletion of SNF5/INI1 in a newly established cell line derived from extrarenal rhabdoid tumor. J Hum Genet 49(10): 586-589, 2004. PMID: 15378398. DOI: 10.1007/s10038-004-0191-y

32 Katsumi Y, Kuwahara Y, Tamura S, Kikuchi K, Otabe O, Tsuchiya K, Iehara T, Kuroda H, Hosoi H and Sugimoto T: Trastuzumab activates allogeneic or autologous antibodydependent cellular cytotoxicity against malignant rhabdoid tumor cells and interleukin-2 augments the cytotoxicity. Clin Cancer Res 14(4): 1192-1199, 2008. PMID: 18281554. DOI: 10.1158/1078-0432.ccr-07-1661

33 Betz BL, Strobeck MW, Reisman DN, Knudsen ES and Weissman BE: Re-expression of hSNF5/INI1/BAF47 in pediatric tumor cells leads to G1 arrest associated with induction of p16 ${ }^{\text {ink4a }}$ and activation of RB. Oncogene 21(34): 5193-5203, 2002. PMID: 12149641. DOI: 10.1038/sj.onc.1205706

34 Ouchi K, Kuwahara Y, Iehara T, Miyachi M, Katsumi Y, Tsuchiya K, Konishi E, Yanagisawa A and Hosoi H: A NOXA/MCL-1 imbalance underlies chemoresistance of malignant rhabdoid tumor cells. J Cell Physiol 231(9): 1932-1940, 2016. PMID: 26680268. DOI: $10.1002 /$ jcp. 25293
35. Kuwahara Y, Mora-Blanco EL, Banine F, Rogers AB, Fletcher C, Sherman LS, Roberts CW and Weissman BE: Establishment and characterization of MRT cell lines from genetically engineered mouse models and the influence of genetic background on their development. Int J Cancer 132(12): 2767 2777, 2013. PMID: 23197309. DOI: 10.1002/ijc. 27976

36 Ciardiello F, Bianco R, Damiano V, De Lorenzo S, Pepe S, De Placido S, Fan Z, Mendelsohn J, Bianco AR and Tortora G: Antitumor activity of sequential treatment with topotecan and anti-epidermal growth factor receptor monoclonal antibody c225. Clin Cancer Res 5(4): 909-916, 1999. PMID: 10213228.

37 Yadav S, Sarkar NDE, Kumari N, Krishnani N, Kumar A and Mittal B: Targeted gene sequencing of gallbladder carcinoma identifies high-impact somatic and rare germline mutations. Cancer Genomics Proteomics 14(6): 495-506, 2017. PMID: 29109099. DOI: $10.21873 / \operatorname{cgp} .20059$
Received August 21, 2020

Revised September 15, 2020

Accepted September 16, 2020 